\title{
Conhecimento Prévio do Perfil Docente em Curso Lato Sensu para uma Formação Personalizada em Modelo Híbrido
}

\author{
Eliana A. M. Leite ${ }^{1,2}$, José A. Lencastre ${ }^{1}$, Bento Silva ${ }^{1}$, Hermínio Borges Neto² \\ ${ }^{1}$ Universidade do Minho, Campus de Gualtar (Uminho) \\ Rua da Universidade, 4710-057, Braga - Portugal \\ ${ }^{2}$ Universidade Federal do Ceará (UFC) \\ Rua Waldery Uchôa, 01, Benfica, CEP 60020-110, Fortaleza- CE -Brasil \\ elimoreiraeadegmail.com, jlencastredie.uminho.pt, bento@ie.uminho.pt, \\ herminio@multimeios.ufc.br
}

\begin{abstract}
This article reports the result of a research that aimed to investigate which identifiable elements or individual profile of a teaching professional in training, cursors at a broad level, in the area of Environmental Education, supported by a hybrid model, considering their singularities, with a view to developing more personalized training scenarios. The methodological screening was based on the qualitative approach, with online questionnaire applications, available to 133 teachers / course participants, and in different variations. The selected and analyzed results of the instruments were parameterized for the pedagogical team on how individualities of the course participants, to prospect the development of the hybrid course, with the emphasis on the potentialities and weaknesses used.
\end{abstract}

Resumo. Este artigo relata resultado de uma pesquisa que teve como objetivo em investigar previamente elementos que identificassem o perfil individual do profissional docente em formação, cursistas em nível lato sensu, na área de Educação Ambiental, apoiado por modelo híbrido, considerando suas singularidades, na perspectiva de elaborar cenários de formação mais personalizados. O percurso metodológico apoiou-se em abordagem qualitativa com aplicação de questionários on-line, disponibilizados aos 133 professores/cursistas, aplicados em periodos diferentes. Os resultados obtidos $e$ analisados dos instrumentos foram parâmetros para situar previamente à equipe pedagógica sobre as individualidades dos cursistas, para prospectar elaboração do curso híbrido, com ênfase nas potencialidades e fragilidades destes sujeitos.

\section{Introdução}

O Ensino híbrido vem sendo discutido como uma abordagem pedagógica que poderá ser sistematizada no processo de ensino-aprendizagem, combinando cenários virtuais e presenciais, para trazer espaços formativos com estratégias de aprendizagem mais flexíveis, autônomos e ajustáveis.

Os processos formativos de professores e estudantes podem ser apoiados por meio do modelo híbrido, corroborando para junção destes cenários, mas que o foco da aprendizagem seja o aprendente. Neste contexto, a formação do profissional docente pode 
ser prospectada numa abordagem formativa híbrida, pois para Belloni (2008), o professor precisa experimentar em sua própria formação situações de atividades para desenvolver com seus alunos. Na concepção de Moran (2015) a educação sempre foi uma mistura de tempos, atividades, práticas metodológicas, uma combinação do presencial e virtual, mas com a "mobilidade e conectividade" tornou-se mais abrangente.

[Monteiro et al. 2015,p.13] aponta que mais do que a integração de modalidades, o ensino híbrido (blended learning), deve ser compreendido como "uma estratégia dinâmica que envolve diferentes abordagens e modelos pedagógicos, diferentes tecnologias e espaços de aprendizagem (formais e informais)".

[Bacich, 2016] considera que no modelo híbrido, a ideia é que educadores e estudantes ensinem e aprendam em tempos e locais variados. Nessa perspectiva, o ensino híbrido favorece a contextos diversos, como a flexibilidade de espaços e formas diferenciadas de aprender. Ademais, poderá beneficiar aos diferentes perfis individuais presentes em um curso, abrangendo um processo de ensino mais personalizado. Em se tratando do docente em formação, o espaço virtual desterritorializado, flexibiliza seu ritmo e tempo, em que poderá conciliar sua formação com as atividades laborais.

Para [Ramos et al. 2019] quanto ao ensino híbrido (b-learning) considera que já não é uma novidade, e pode incorporar mais recursos tecnológicos ao processo de ensinoaprendizagem, bem como pode promover maior motivação dos professores e estudantes.

$\mathrm{Na}$ concepção de [Albuquerque et al. 2017] a sociedade está cada vez mais imbricada numa sociedade virtual, configurada pela presencialidade deste virtual. Diversos setores da sociedade cada vez mais têm realizado essa conexão entre o virtual e o presencial, [Valente, 2015], ressalta que a educação ainda não passou por essa inovação, mas que existe a tentativa de realizar essas mudanças nos processos educacionais. Contudo, para que a educação alcance este processo de inserção do ensino híbrido, como uma sistematização nas práticas pedagógicas, é fundamental o papel do profissional docente na funcionalidade deste processo.

Para tanto, o (a) professor(a) poderá contribuir como sujeito ativo da própria formação, sendo considerado protagonista, a partir de elementos que investiguem a opinião do profissional docente, para que suas experiências e saberes sejam valorizados. Instituições responsáveis pelos processos formativos podem elaborar formações colaborativamente a partir dessas opiniões e experiências dos docentes. Dessa forma, é fundamental investigar o conhecimento prévio dos perfis do (a) professor (a), referente aos tipos de cursos que já fizeram, motivos que os levam a participar das formações, as tecnologias digitais que usam, redes sociais que acessam, dentre outras informações. [Pretto et al. 2020] apresentam reflexões das possibilidades e oportunidades para uma formação de professores que contemple de forma efetiva as tecnologias digitais, e se garantida as condições mínimas pode ser que se torne uma realidade ..."sendo que deve ser centrada na horizontalidade e nas trocas constantes, e não numa rede de distribuição".

No que tange a capacitação dos profissionais, quanto a formação para o ensino híbrido, [Diniz et al. 2019] relatam um mapeamento sistemático sobre o ensino híbrido, aplicado a capacitação de profissionais no período de 2014 a 2018. Estes autores, apontam que a temática é bem difundida no ambiente educacional de modo geral, sobretudo na educação formal curricular. Contudo, consideram que se trata de um tema ainda escasso, quando o enfoque é aplicado diretamente à capacitação profissional. Neste contexto, o docente sendo capacitado profissionalmente no e para o ensino híbrido (b-learning), 
poderá trazer para a sala de aula abordagens pedagógicas similares. Ressalta-se, que para elaborar um curso híbrido, implica em delinear um planejamento cuidadoso, pois os aprendentes em cenários que integram o virtual e o presencial apresentam necessidades e características diversas, haja visto que ambientes virtuais e presenciais tem especificidades próprias. Para Belloni [2008] não basta transferir um curso de um ambiente presencial para um ambiente virtual, sem conhecer o público que irá desenvolver um curso.

Diante deste contexto, este trabalho teve como objetivo investigar previamente elementos que identifiquem o perfil individual do profissional docente em formação continuada em curso lato sensu na área de Educação Ambiental, apoiado por um modelo híbrido, considerando suas singularidades, na perspectiva de elaborar cenários de formação mais personalizados.

Este trabalho está organizado nas seguintes seções: na segunda seção abordam-se os procedimentos metodológicos empregados; na terceira seção é apresentado os resultados e discussões do estudo, e por fim, apresentam-se as considerações finais.

\section{Procedimentos Metodológicos}

A metodologia adotada neste trabalho foi de natureza qualitativa de forma exploratória. Para Creswell (2014), em relação à pesquisa qualitativa, quando se adota este formato, a intenção é o estudo de múltiplas realidades. Nesse sentido, a partir dos dados coletados por meio dos instrumentos aplicados, descrevem-se dados e características acerca dos professores/cursistas, oriundos de diversos cenários educativos, com perfis diferenciados.

O universo da pesquisa foram professores da educação básica, cursistas de um curso lato sensu em Educação Ambiental (EA), ofertado por uma Universidade pública, selecionados por meio de edital público. Os professores/cursistas eram de vários municípios de escolas públicas do estado do Ceará, que mensalmente tinham encontros presenciais no campus da Universidade. Neste contexto, a formação ocorreu em modelo híbrido, com início em 2017 e conclusão em 2019, com a adoção de encontros presenciais sistemáticos e com a utilização de um Ambiente Virtual de Aprendizagem e Ensino (AVAE), apoiado pela plataforma Moodle. No AVAE, foram implementados os recursos digitais, bibliotecas, atividades virtuais síncronas e assíncronas, para interação e colaboração entre cursistas e professores do curso.

Para coleta de dados, foram aplicados dois questionários, cada um com quantidade de questões diferentes, disponibilizados para 133 cursistas/matriculados (as). O grupo foi esclarecido sobre a relevância deste estudo e voluntariamente preencheram os Termos de Consentimento e Livre Esclarecimento (TCLE). A pesquisa obteve aprovação do Comitê de Ética e Pesquisa de uma universidade pública do Estado do Ceará, protocolado sob o número CAAE: 03340818.9.0000.5054. Ressalta-se, que a participação era voluntária, portanto, alguns dos cursistas não responderam os instrumentos. Os questionários foram elaborados em formato on-line e apresentaram questões objetivas e subjetivas: (1) $\mathrm{O}$ primeiro questionário intitulado por "Queremos conhecer você" foi disponibilizado na página inicial do ambiente virtual Moodle; (2) O segundo questionário teve aplicação ao término da primeira disciplina "Introdução ao Curso e ao Ambiente Virtual", viabilizado no mural da disciplina, por meio de um link para que pudessem ter acesso. A seguir, apresentam os resultados e discussões. 


\section{Resultados e discussões}

Os resultados adquiridos da pesquisa foram tabulados e apresentados de acordo com os dados compilados a seguir. A pesquisa procurou saber por meio da questão 1 se os cursistas possuíam curso de pós-graduação e se respondido afirmativamente, a questão 2 , indagava qual nível estava vinculado: especialização; ( ) mestrado; ( ) doutorado ( ). Para a questão 1, tivemos 100 respondentes, 62 cursistas (62\%) que tinham concluído pósgraduação e 38 cursistas que não haviam cursado (38\%). Referente a questão 2 , foram obtidas respostas de 60 cursistas em que haviam concluído pós-graduação lato sensu e duas cursistas em nível de pós-graduação stricto sensu (mestrado). O índice percentual de cursistas, com pós-graduação, foi um dado que chamou atenção, mesmo que o curso trouxesse novos conhecimentos, poderia ocorrer desmotivação para concluir o curso. Ressalta-se, que o acúmulo de cursos em pós-graduação lato sensu não acarreta benefícios em termos de gratificação salariais no plano de carreira do magistério da rede pública do estado, em que este público de cursistas são docentes.

Quanto à questão 3, foi indagado se o cursista já teria participado de cursos na modalidade EaD: sim ( ); não ( ); Se a resposta anterior fosse sim, na questão 4 deveria relatar qual (is) curso (s) foram realizados. Nesta questão, 72 cursistas $(70 \%)$ não haviam realizado cursos em EaD e 31 cursistas (30\%) responderam afirmativamente. $\mathrm{O}$ quantitativo de cursistas sem cursos na modalidade (70\%), se tornou um dado relevante e preocupante, pois poderia ocasionar evasão, devido à falta de conhecimento dos cursistas com a modalidade, uma vez que poderiam ter dificuldades de adaptação com a nova proposta de formação. Ademais, a questão 4, referentes aos cursos EaD realizados foram diversificados, a saber, como cursos de: licenciatura plena; graduação em administração; curta duração em educação ambiental (Com Vidas); extensão em Educação de Jovens e Adultos (EJA); educação inclusiva; prevenção de drogas, dentre outros.

No que tange a questão 5, como ocorria o acesso à Internet: fácil ( ); razoável ( ); difícil ( ). Neste contexto, 91 cursistas $(88,3 \%)$ afirmaram que o acesso era fácil, nove cursistas $(8,7 \%)$ colocaram razoável, três cursistas $(3 \%)$ apontaram de difícil acesso (Figura 1). Este dado, poderia sinalizar que $88,3 \%$ dos cursistas teriam mais facilidade de acesso as atividades e interação no ambiente on-line, sendo um fator que representaria maior possibilidade para acompanharem o curso. Contudo, o acesso razoável e difícil, com percentual de $11,7 \%$, apesar de ser um índice pequeno, foram dados que mereceram atenção. O processo formativo do docente reverbera na sua práxis em sala de aula, e quando ocorre a desistência deste profissional, a lacuna fica na sua formação, mas também implica que outros conhecimentos não chegaram até os estudantes. 
IX Congresso Brasileiro de Informática na Educação (CBIE 2020)

Anais do XXVI Workshop de Informática na Escola (WIE 2020)

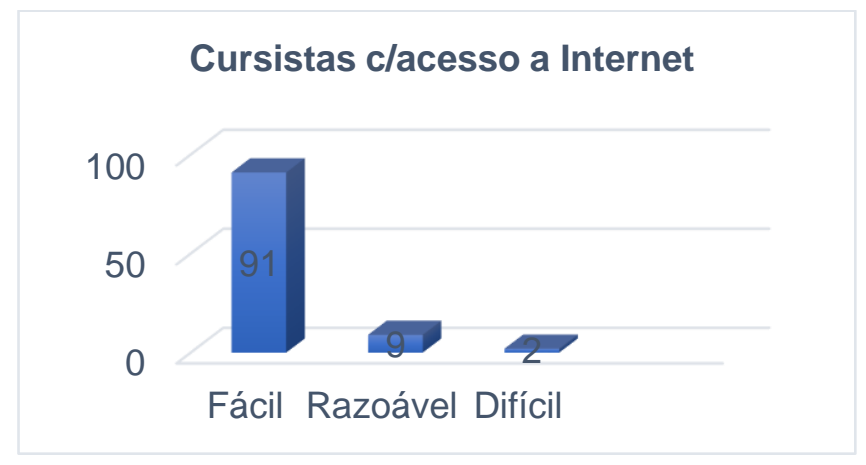

Figura 1. Gráfico "acesso à Internet"

Fonte: elaboração própria

Relativo a questão 6, solicitou: assinale a(s) rede (s) social (is) mais usadas: Linkedin ( ); Instagram ( ); Facebook ( );WhatsApp ( ) e outras ( ). Ressalta-se que poderiam escolher mais de uma opção, mas deveria colocar por ordem de preferência. A predominância foi a rede social whatsapp, em segundo lugar Facebook e terceiro lugar, o Instagram (Figura 2). Para tanto, o Wathsapp, sendo predominante, se constituiu também como uma rede social que facilitou a comunicação mais imediata entre os pares durante o período do curso.

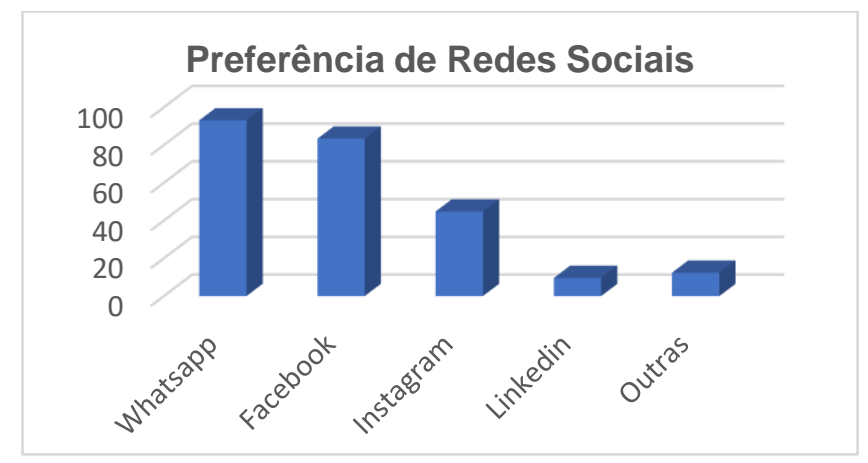

Figura 2. Gráfico "preferência pelas redes sociais"

Fonte: elaboração própria

Para a questão 7, pergunta-se: qual sua capacidade para desenvolver atividades em grupo: excelente ( ); boa ( ); c. razoável ( ). Neste contexto, 59 cursistas (46,9\%) afirmaram que possuíam uma boa capacidade, 34 afirmaram $(44,3 \%)$ que tinham excelente capacidade, e dez respondentes $(25,5 \%)$ afirmaram que tinham razoável capacidade (Figura 3). Os dados possibilitaram a realização de atividades colaborativas, chats, fóruns, wikis (textos colaborativos), assim como também atividades individuais, portfólios e quizes (questionários individuais). Nas aulas presenciais, as atividades em grupo também foram promovidas, por meio de seminários, oficinas, palestras. 
IX Congresso Brasileiro de Informática na Educação (CBIE 2020)

Anais do XXVI Workshop de Informática na Escola (WIE 2020)

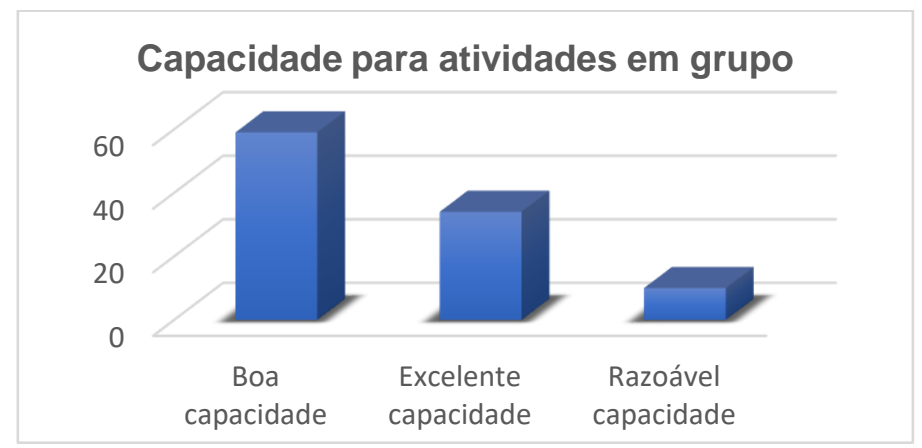

Figura 3. Gráfica "capacidade para atividades em grupo"

Fonte: elaboração própria

Quanto à questão 08: qual(is) motivos levaram a fazer a seleção para este curso? 1.- ampliar o aprendizado; 2-obter ascensão funcional; 3- possuir muita afinidade com a área. Marque a resposta: item 1 ( ); item 2; ( ) item 3; ( ) 1 e 2 ; ( ) 1e 3; ( ) 2 e 3; ( ) 1, 2 e 3. Nesta questão, foram coletados dados de 97 respondentes. Dos itens elencados e respondidos, a opção mais escolhida pelos cursistas foi "ampliar o aprendizado" (26\%), em seguida veio ampliar o aprendizado e pela afinidade com a área $(16 \%)$ e como terceira opção, afinidade pela área (15\%) (Figura 4). O menor percentual se refere a ascensão funcional $(1 \%)$, podendo ser um dado corroborado pela quantidade de cursistas que já possuíam cursos de pós-graduação. Em termos de ascensão funcional para carreira docente da educação básica, é válido somente um curso de pós-graduação lato sensu e stricto sensu.

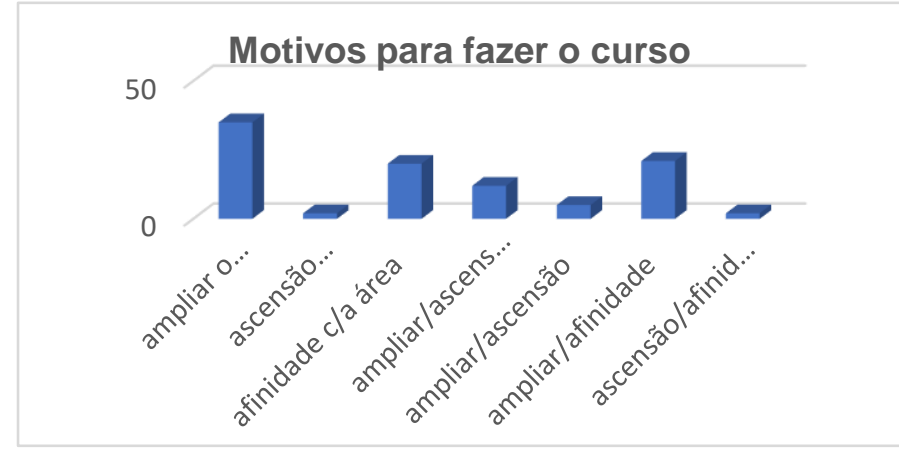

Figura 4. Gráfico "motivos para fazer o curso"

Fonte: elaboração própria

No segundo questionário, foram analisadas seis questões. As questões 1 e 2 foram adaptadas, na perspectiva do Inventário de Estilo de aprendizagem de David Kolb (1976), relacionadas as questões metacognitivas, que fazem o/a estudante pensar sobre si mesmo(a), como processa seu aprendizado. Neste contexto, a questão 1 indaga sobre a realização de atividades: "aprendo melhor quando estou: (a) fazendo; (b) observando; (c) pensando; (d) sentindo. Para tanto, 73 cursistas (63\%) optaram pelo item a, "fazendo" atividades, em seguida 25 cursistas $(21,5 \%)$ colocaram "observando", em terceira colocação 15 cursistas (13\%) responderam quando estão "pensando" e três cursistas $(2,6 \%)$ optaram em dizer que aprendem melhor quando estão "sentindo (Figura 5). 


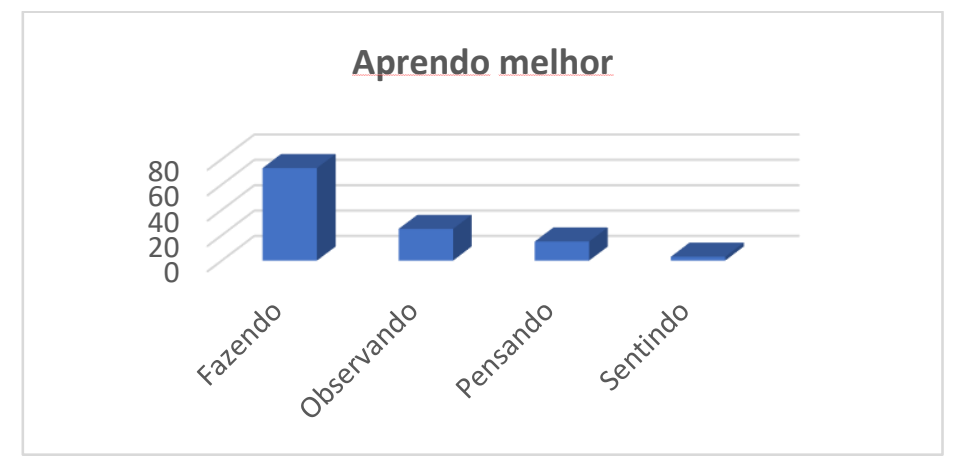

Figura 5. Gráfico "aprendo melhor ao realizar atividades"

Fonte: elaboração própria

No que se relaciona a questão 2, você aprende melhor: (a) experimentando e praticando; (b) pela observação; (c) pelas interações pessoais; (d) pelas teorias racionais. As respostas foram: 71 cursistas $(60 \%)$ responderam o item a, "experimentando e praticando, 27 respondentes $(23 \%)$ colocam ser pela observação, e 15 respondentes $(12,8 \%)$ apontam que seria pelas "interações pessoais" e quatro cursistas $(3,4 \%)$ por meio das "teorias racionais" ( Figura 6). Observa-se pelas respostas das questões 1 e 2, que as opções escolhidas pelos/as cursistas se identificam com atividades que estão voltadas para ações práticas, seja pelo fazer, experimentar e praticar. Neste contexto, foram elaboradas atividades, no âmbito presencial e virtual, para que apresentassem situações práticas vivenciadas nos cenários educativos com os estudantes no âmbito da Educação Ambiental.

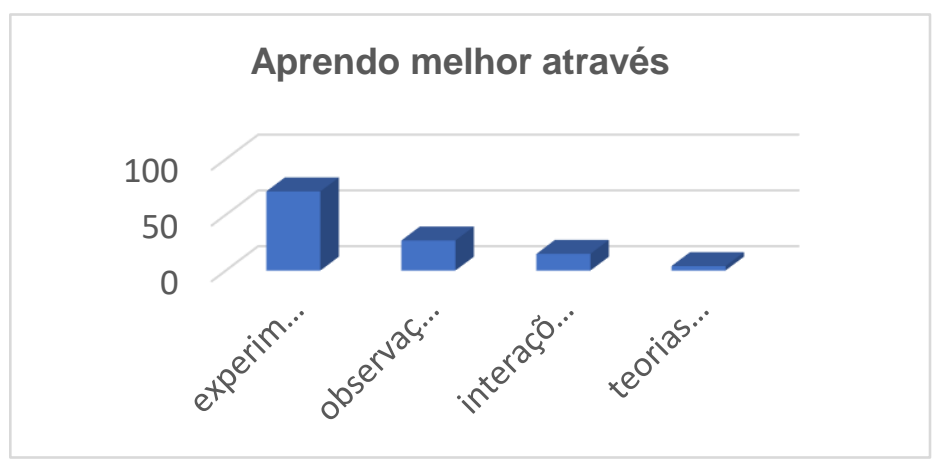

Figura 6. Gráfico "aprendo melhor"

Fonte: elaboração própria

Quanto as questões 3 e 4, pode se estabelecer um paralelo entre elas, uma vez que é indagado aos cursistas, na questão 3 qual ferramenta do ambiente virtual mais gostaram de interagir, assim como, na questão 4, qual sentiram mais dificuldade. Para a questão 3 , 48 cursistas apontam o fórum como ferramenta de maior afinidade (Figura 7) e 75 cursistas apresentaram o Wiki (texto colaborativo) como recurso que sentiram mais dificuldade (Figura 8). Fazendo um cruzamento de dados coletados com o primeiro questionário aplicado "Queremos conhecer você", relativo à questão 7 (capacidade para desenvolver atividades em grupo), 93 cursistas (81\%) responderam que tinham entre boa e excelente capacidade. Contudo, apesar do Wiki ser uma ferramenta colaborativa, não obteve uma boa aceitação pelos professores/cursistas. Percebe-se, que foi a partir do momento que os/as cursistas entraram em contato direto com as ferramentas do AVAE, 
que puderam avaliar com mais precisão aquelas que proporcionaram mais facilidade e dificuldade de uso.

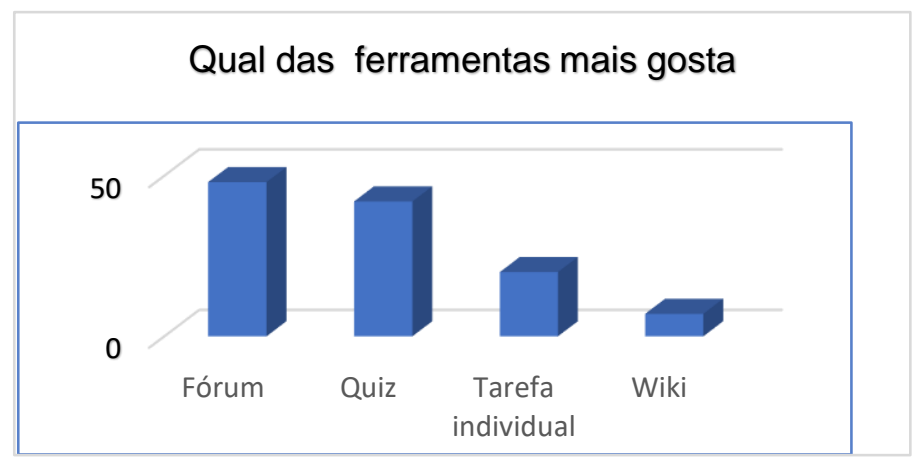

Figura 7. Gráfico "ferramenta que mais gosta"

Fonte: elaboração própria

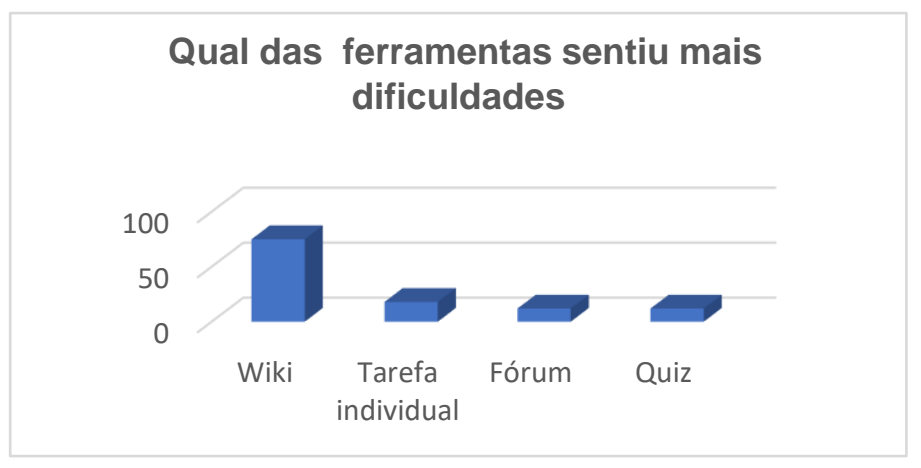

Figura 8. Gráfico "ferramenta que sentiu dificuldades"

Fonte: elaboração própria

Com relação ao sentimento para a realização das tarefas, no que tange a questão 5, posto como primeira colocação, 37 cursistas responderam que se sentiam tranquilos (as), em segunda colocação, 33 respondentes sentem muitas dificuldades devido ao trabalho, como terceira opção 31 cursistas consideram "pouco tempo para realização das atividades" e na quarta colocação, 14 cursistas se sentem pressionados pelos prazos das demandas das atividades previstas na agenda do curso (Figura 09). As demandas relacionadas à profissão, podem trazer dificuldades para conciliar com as atividades do curso. Para tanto, fez-se necessário que a equipe pedagógica e professores das disciplinas, fossem flexíveis, ajustassem prazos, bem como, disponibilizassem vias de acesso por emails, contatos telefônicos, redes sociais, para que os/as cursistas fossem ouvidos (as), e pudessem relatar suas dificuldades, quando preciso. 


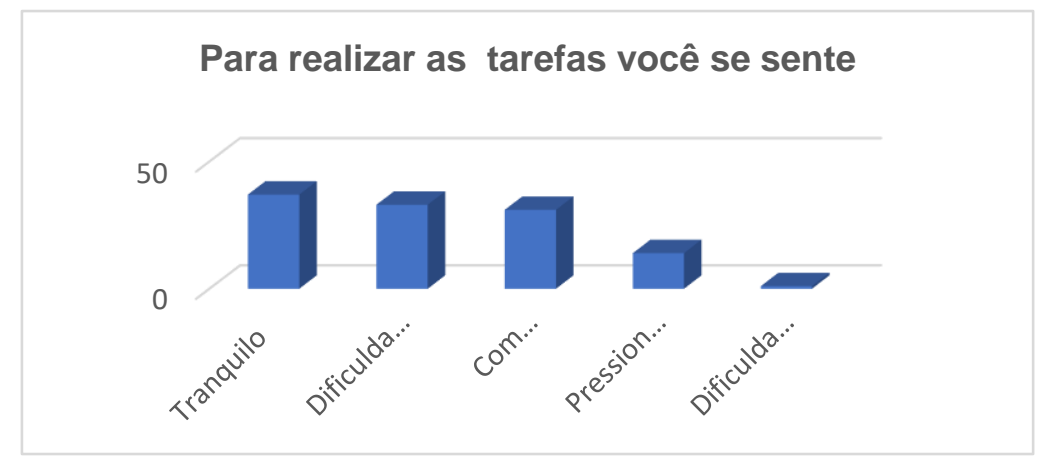

Figura 9. Gráfico "sentimento para realizar as tarefas"

Fonte: elaboração própria

Quanto à questão 6, no que se refere, aos recursos que mais gostavam quando presentes nas atividades, foram obtidos os resultados: 58 cursistas $(49,5 \%)$ preferência pelos vídeos, 36 cursistas (30,7\%) optaram pelas leitura de textos e artigos,19 respondentes $(16,2 \%)$ escolheram," imagens", três cursistas ( $2,5 \%)$ optaram pelas músicas e um cursista $(0,85 \%)$ optou por jogos (Figura 10). Os vídeos foram usados na elaboração de atividades individuais e coletivas para possibilitar reflexão e discussão entre os pares. Quanto aos jogos, é um indicador de um público que não possui muita familiaridade com este recurso.

\section{Você gosta mais de atividade que têm}

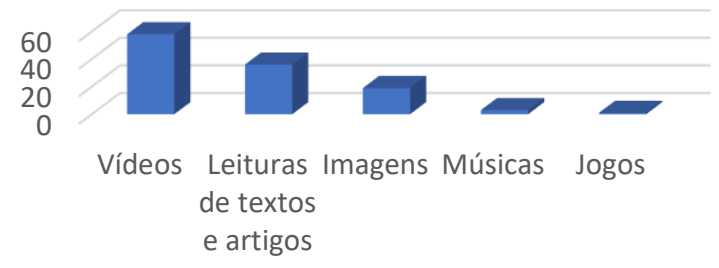

Figura 10. Gráfico "preferências de recursos nas atividades"

Fonte: elaboração própria

\section{Considerações Finais}

O presente estudo teve como objetivo investigar previamente elementos que identificassem o perfil individual de docentes em formação, cursistas em nível lato sensu, apoiado por um modelo híbrido. Para tanto, os dados coletados permitiram identificar singularidades dos/as cursistas, na perspectiva de elaborar cenários mais personalizados. Estas informações auxiliaram a perceber potencialidades e fragilidades dos docentes e assim foi possível fazer ajustes necessários no design do curso, durante o percurso formativo.

O conhecimento prévio dos perfis individuais dos cursistas corroborou como possibilidade para o desenho do curso híbrido mais próximo da realidade dos professores/cursistas, relacionados as suas potencialidades, mas também foi parâmetro para o conhecimento dos pontos mais frágeis. Ressalta-se, que os desafios são bem maiores para elaborar um curso com design personalizado, que venha a atender ao ensino híbrido, mas que pode colaborar para atender necessidades dos cursistas, ocasionando formações mais flexíveis, que considere as especificidades dos aprendentes. Dessa forma, ter conhecimento das idiossincrasias do profissional docente, poderá ser indicativo para elucidar estratégias formativas que valorize às suas particularidades e experiências. Para 
se alcançar dimensões efetivas de transformação no campo da formação para professores é preciso que estejam engajados, para que se empoderem dos conhecimentos necessários a sua profissionalidade, e assim, tornem-se protagonistas de suas formações.

\section{Referências Bibliográficas}

Albuquerque, M., Sales, G. L., Rebouças Filho, P., and Medeiros, C. (2017). Avaliação da presencialidade em um fórum LV utilizando lógica fuzzy. In Brazilian Symposium on Computers in Education (Simpósio Brasileiro de Informática na Educacão -SBIE), volume 28, page 1357.

Bacich, L., Neto, A. T, Trevisan, F. Mode.M. (2015). Ensino híbrido:personalização e tecnologia na educação.En XX. Bacich, L.,Neto, A.T., Trevisani, F.de M (Penso), Ensino híbrido:personalização e tecnologia na educação (pp.47-53) . Porto Alegre: Penso.

Bacich, L. (2016). Ensino Híbrido: Proposta de formação de professores para uso integrado das tecnologias digitais nas ações de ensino e aprendizagem. In V Congresso Brasileiro de Informática na Educação (CBIE 2016) - Anais do XXII Workshop de Informática na Escola (WIE 2016), volume 27, page 973.

Belloni, M. L. (2008). Educação a Distância. Campinas, 5.ed.SP: Autores Associados.

Creswell, J. W. (2014). Investigação Qualitativa e Projeto de Pesquisa. Tradução: Sandra Mallman de Rosa; revisão técnica: Dirceu da Silva. - $3^{\text {a }}$ ed. - Dados eletrônico. Porto Alegre: Penso.

Diniz, I. J. and Gomes, A. V. (2019). Ensino Híbrido Aplicado a Capacitações Profissionais: Um Mapeamento Sistemático da Literatura. In VIII Congresso Brasileiro de Informática na Educação (CBIE 2019) - Anais do XXV Workshop de Informática na Escola (WIE 2019), volume 30, page 1494.

Kolb, D. (1976). Learning Style Inventory. Boston: Hay Group.

Monteiro, A., Moreira, A. \& Lencastre, J. A. (2015). Blended (E) learning na sociedade digital. Coleção: Estudos Pedagógicos/ Dinâmicas Educacionais Contemporâneas. Portugal: WHITEBOOKS.

Moran, J. (2015). Educação híbrida: um conceito-chave para a educação, hoje. En:xx. . Bacich, L., Neto, A.T., Trevisani, F. de M (Penso). Ensino híbrido:personalização e tecnologia na educação (pp.27-45) . Porto Alegre: Penso.

Pretto, N.de.L; Bonilla, M. H. S; Sena, I.P.F. de S. (2020). Educação em tempos de pandemia:reflexões sobre as implicações do isolamento físico imposto pelo COVID19. Salvador : Edição do autor, 18p.

Ramos, J. L.C; Silva, R. F. P.; Silva, J. C. S.; Gomes, A. S (2015). Estudo comparativo entre ambientes virtuais para uso em Blended Learning na Universidade Federal do Vale do São Francisco. In VIII Congresso Brasileiro de Informática na Educação (CBIE-LACLO, 2015) - Anais do XXI Workshop de Informática na Escola (WIE 2015), volume 26, page 1494.

Valente, J. A. (2015). O ensino híbrido veio para ficar. En:xx. .Bacich, L., Neto, A.T., Trevisani, F. de M (Penso). Ensino híbrido:personalização e tecnologia na educação (pp.13-17) Porto Alegre: Penso 